\title{
Black Pepper Leaf Oil Mass Spectrometric Profile Variations in the Southern Western Ghats of India
}

\author{
Paul Joseph T \\ Navy Children School, Kochi \\ 11/828 K.J. Herschel Road \\ Kochi 682001, Kerala, India
}

\author{
N.S. Kalesh, $\mathrm{PhD}$ \\ Interfield Laboratories \\ 13/1208 R.K. Pillai Road \\ Kochi 682005, Kerala, India
}

\begin{abstract}
Piper nigrum leaves were collected from five locations from Kerala within a radius of $150 \mathrm{~km}$, altitudinal variance of $1000 \mathrm{~m}$ and annual rainfall variance of $1400 \mathrm{~mm}$. The extracted Piper nigrum leaf oil was profiled using a GC-MS, Beta Caryophyllene was the only constituent that was present in all the five locations, of which the highest concentration was noted in the high altitude region of Idukki. Micro-climate plays a vital role in the production of these constituents, as samples from the low range areas of Idukki and high range areas of Idukki did not have similar oil profiles. High amounts of Alpha Pinene were present in the sample from the low range region of Idukki whereas in the sample from the high range region of Idukki showed extremely high concentrations of Elemol. There is also great variation in concentrations of chemicals like Beta Gurjunene, Copaene and Germacrene D. This shows that the variance of micro-climate and microenvironmental factors like soil plays a significant role in the concentrations of certain phytochemicals in the Piper nigrum leaf volatile oil profile. Black pepper has recently been geographically indicated (GI tagged). The variations found in the leaf oil profile of the piper nigrum could help in reducing the abuse of the GI system.
\end{abstract}

\section{General Terms}

Mass Spectrometry, Gas Chromatography, NIST 2.0, Chemometrics

\section{Keywords}

Piper nigrum, Black pepper, Leaf oil, Geographic Indication, Oil profile.

\section{INTRODUCTION}

Piper nigrum is an extremely important and useful spice, paired with salt, it is on almost every tabletop. History says that even back in the old days people used to consider it a highly valuable commodity. At the time most people used to call it 'black gold', signifying its value. In fact, it was what made Christopher Columbus, the great Italian explorer; go in search of the source of this spice, to Kerala.

Piper nigrum is native to south India and thrives in tropical hot and humid climate. It grows the best when the soil temperature is above $75^{\circ} \mathrm{F}$. The soil must be rich in humus, soft and loamy. The optimum $\mathrm{pH}$ of the soil must be between $5.5-6$. There should be approximately $2000 \mathrm{~mm}$ or more of annual rainfall

It is interesting to explore more about the oil profile and various phyto constituents in Piper nigrum leaves. The study will give valuable information about the connection, if any, between phyto constituents and the geographical area where it was grown. The analysis of micro environmental factors such as altitude, temperature and rainfall will give information about the variations in its oil profile. We will also gain information on variation in the concentration levels of certain phytochemicals of the Piper nigrum leaves i.e., what environmental conditions are the ideal to have high concentrations of a certain phytochemical. Just like how sparkling white wine from anywhere other than champagne cannot be called champagne (it has been GI tagged), Piper nigrum that is grown in the Thalassery district of Kerala has also recently been GI tagged.

Hence the main objectives of our study are:

1. To explore the volatile oil profile of Piper nigrum leaves.

2. To study whether the oil profile of the leaves vary with varying environmental factors.

\section{MATERIALS AND METHODS}

Piper nigrum leaves were collected from different locations in Kerala namely Kollam, Idukki (High range and low range), Ernakulum and Wayanad. The volatile oils were extracted from each of these samples, followed by an oil profile using a GC-MS. The micro environmental factors are illustrated in Table 1.

\subsection{Estimation of essential oil from Piper nigrum leaves by hydro distillation using Clevenger's method. (Clevenger, J. F. 1928)}

Approximately $250 \mathrm{~g}$ of the sample was taken and transferred to a round-bottomed flask and water was added. The volatile oil was extracted by hydro distillation method using the Clevenger apparatus. After three hours the extracted oil yield was noted.

Table 1: - Micro environmental factors associated with the collection spots of samples (Climate of Kerala, 2014)

(Climate Wayanad, 2014) (MSN Weather, 2014) (Weather in Ernakulum)

\begin{tabular}{|c|c|c|c|}
\hline Locations & $\begin{array}{c}\text { Altitude } \\
\text { (Mean Sea } \\
\text { Level) }\end{array}$ & $\begin{array}{c}\text { Temperature } \\
\text { (annual) }\end{array}$ & $\begin{array}{c}\text { Rainfall } \\
\text { (annual) }\end{array}$ \\
\hline Kollam & $50 \mathrm{~m}-100 \mathrm{~m}$ & $26^{\circ} \mathrm{C}-29^{\circ} \mathrm{C}$ & $2500 \mathrm{~mm}$ \\
\hline Idukki (LR)* & $50 \mathrm{~m}-100 \mathrm{~m}$ & $23^{\circ} \mathrm{C}-29^{\circ} \mathrm{C}$ & $2700 \mathrm{~mm}$ \\
\hline $\begin{array}{c}\text { Idukki } \\
(\text { HR)** }\end{array}$ & $\begin{array}{c}500 \mathrm{~m}- \\
1000 \mathrm{~m}\end{array}$ & $17^{\circ} \mathrm{C}-20^{\circ} \mathrm{C}$ & $2900 \mathrm{~mm}$ \\
\hline Ernakulum & $50 \mathrm{~m}-100 \mathrm{~m}$ & $24^{\circ} \mathrm{C}-30^{\circ} \mathrm{C}$ & $2500 \mathrm{~mm}$ \\
\hline
\end{tabular}




\subsection{GC-MS analysis of essential oil from Piper nigrum leaves.}

The extracted oils were diluted 50x in dichloromethane. The analysis was carried out in Agilent GC $6890 \mathrm{~N}$ and the detector was MS 5975. The column oven was programmed as follows: $50^{\circ} \mathrm{C}-100 \mathrm{C}$ at the rate of $5 \mathrm{C} / \mathrm{min}$ then $3 \mathrm{C} / \mathrm{min}$ up to $250^{\circ} \mathrm{C}$ and the hold time is $5.0 \mathrm{~min}$ at $250^{\circ} \mathrm{C}$. The carrier gas used in the analysis was helium and the flow rate $0.7 \mathrm{ml} / \mathrm{min}$. The injection port temperature was maintained at $250^{\circ} \mathrm{C}$. The column used for the analysis was DB-5MS. The total run time was $65 \mathrm{~min}$. The compounds whose concentrations were observed to be higher than $1 \%$ is tabulated in Table 2 .

Table 2: - GC/MS profiling of Volatile oil constituents (\%) of Piper nigrum from different locations

\begin{tabular}{|c|c|c|c|c|c|}
\hline \multirow[b]{2}{*}{ Compounds } & \multicolumn{5}{|c|}{ Location } \\
\hline & A & B & $\mathrm{C}$ & D & $\mathrm{E}$ \\
\hline Alpha Pinene & - & 13.72 & 1.14 & 9.84 & 3.28 \\
\hline Beta Pinene & - & 2.24 & - & 1.37 & - \\
\hline $\begin{array}{l}\text { Beta } \\
\text { Caryophyllene }\end{array}$ & 2.07 & 1.76 & 2.25 & 2.20 & 1.94 \\
\hline Germacrene D & 4.21 & 14.34 & 2.60 & 2.28 & - \\
\hline $\begin{array}{l}\text { Beta } \\
\text { Bisabolene }\end{array}$ & - & 1.17 & - & - & - \\
\hline $\begin{array}{l}\text { Alpha } \\
\text { Amorphene }\end{array}$ & - & 2.48 & - & - & - \\
\hline Alpha Elemene & - & 1.59 & - & - & - \\
\hline Copaene & 6.84 & 4.38 & - & - & 21.88 \\
\hline $\begin{array}{l}\text { Alpha } \\
\text { Eudesmol }\end{array}$ & - & 2.54 & 9.18 & - & - \\
\hline $\begin{array}{l}\text { Alpha } \\
\text { Cubebene }\end{array}$ & 1.16 & - & - & 1.01 & 1.91 \\
\hline Beta Elemene & 1.66 & - & - & - & 1.28 \\
\hline $\begin{array}{l}\text { Alpha } \\
\text { Gurjunene }\end{array}$ & 1.45 & - & - & 1.30 & 2.30 \\
\hline $\begin{array}{l}\text { Gamma } \\
\text { Elemene }\end{array}$ & 1.14 & - & - & 2.91 & 2.22 \\
\hline Eremophilene & 4.32 & - & - & 4.47 & 7.15 \\
\hline Beta Gurjunene & 12.39 & - & 1.324 & 13.36 & - \\
\hline Spathulenol & 1.77 & - & - & - & 1.55 \\
\hline $\begin{array}{l}\text { Gamma } \\
\text { Guaiene }\end{array}$ & 1.62 & - & - & - & - \\
\hline Gamma & 1.23 & - & 1.48 & - & - \\
\hline
\end{tabular}

\begin{tabular}{|l|c|c|c|c|c|}
\hline Cadinene & & & & & \\
\hline $\begin{array}{l}\text { Gamma } \\
\text { Cadinol }\end{array}$ & 9.97 & - & 4.11 & - & - \\
\hline Elemol & - & - & 32.98 & 2.98 & - \\
\hline Nerolidol & - & - & 8.90 & - & - \\
\hline $\begin{array}{l}\text { gamma } \\
\text { Eudesmol }\end{array}$ & - & - & 7.68 & - & - \\
\hline Ledene & - & - & - & 8.60 & - \\
\hline Beta Cadinene & - & - & - & 3.73 & - \\
\hline $\begin{array}{l}\text { Geranyl } \\
\text { acetone }\end{array}$ & - & - & - & 1.07 & - \\
\hline Isoledenme & - & - & - & 1.25 & - \\
\hline Germacrene & - & - & - & - & 2.42 \\
\hline Delta Cadinene & - & - & - & - & 7.21 \\
\hline Delta Guaiene & - & - & - & - & 1.36 \\
\hline Alpha Cadinol & - & - & - & - & 1.63 \\
\hline Farnesol & - & - & - & - & 1.86 \\
\hline Delta Elemene & 2.91 & - & - & - & - \\
\hline Total & 13 & 9 & 10 & 12 & 14 \\
\hline
\end{tabular}

A- Kollam; B- Idukki (Low Range); C- Idukki (High Range); D- Ernakulum; E- Wayanad.

\section{RESULTS}

The highest yield of essential oils was observed in samples which were collected from the Idukki district of Kerala, shown in Table 1. The GC-MS oils profile of the leaves gives us the following data, shown in Table 3. The chromatograms of the respective accessions are shown in Images 1 to 5 .

Table 3: - Yield of essential oil obtained after hydro distillation

\begin{tabular}{|c|c|c|}
\hline Sample ID & location & Yield (\%) \\
\hline Acc. 1 & Idukki (LR) & $0.3 \%$ \\
\hline Acc. 2 & Kollam & $0.1 \%$ \\
\hline Acc. 3 & Idukki (HR) & $0.3 \%$ \\
\hline Acc. 4 & Ernakulum & $0.15 \%$ \\
\hline Acc. 5 & Wayanad & $0.14 \%$ \\
\hline
\end{tabular}

LR- Low Range; HR- High range 

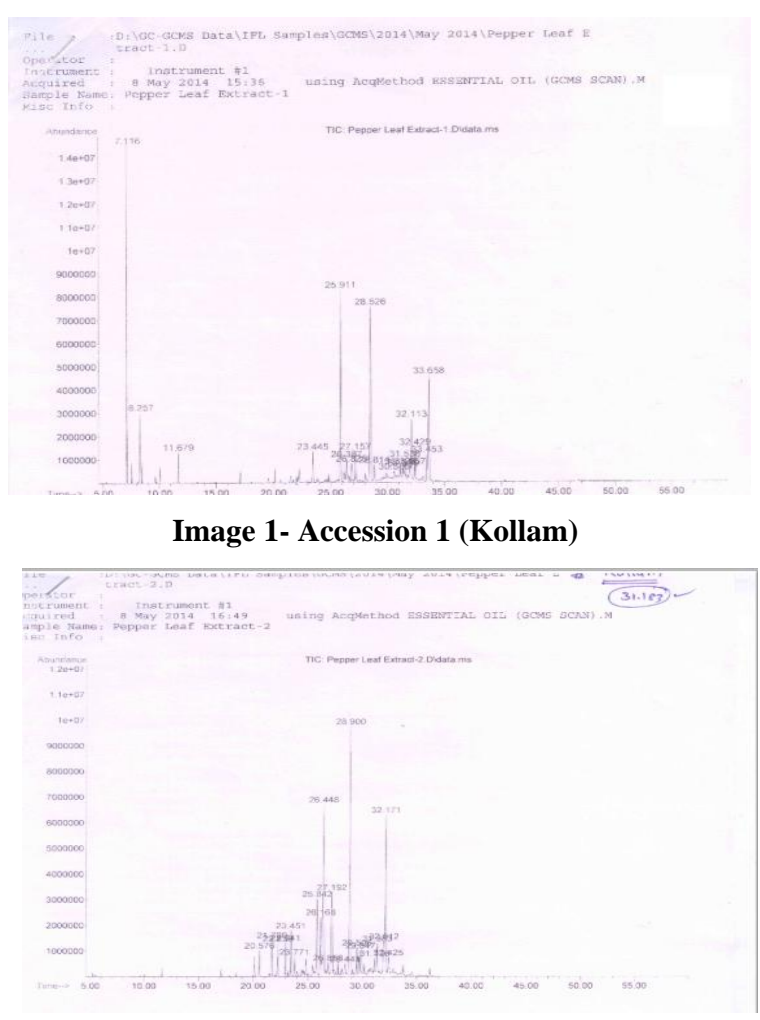

Image 2- Accession 2 (Idukki low range)

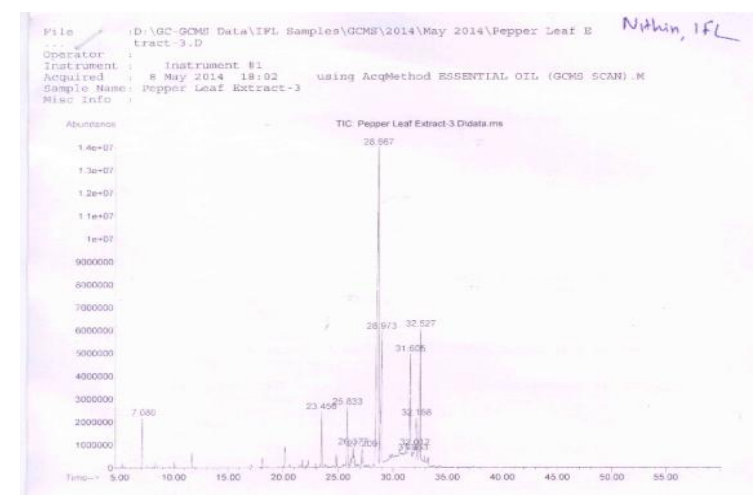

Image 3- Accession 3 (Idukki high range)

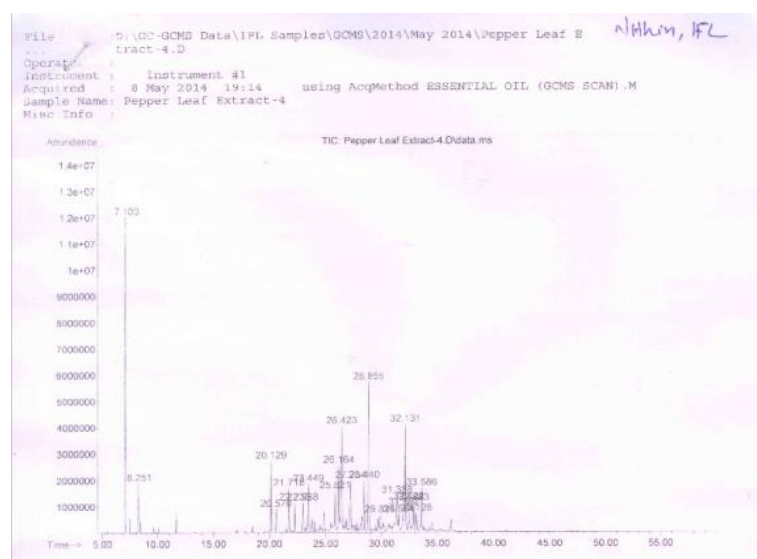

Image 4- Accession 4 (Ernakulum)

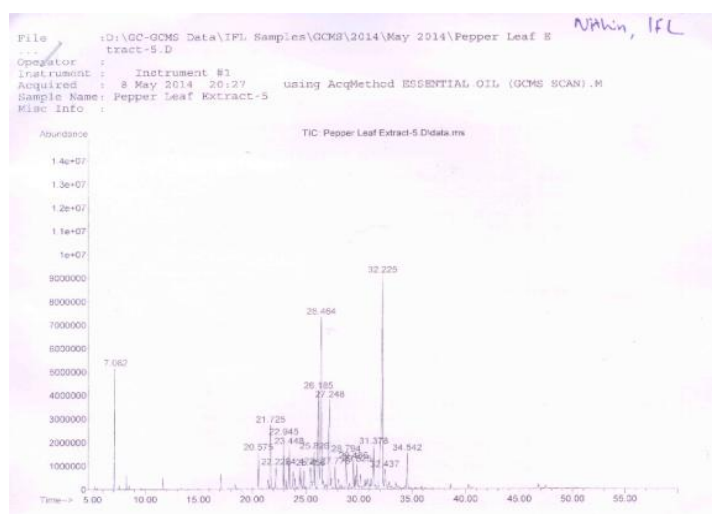

Image 5- Accession 5 (Wayanad)

\section{CONCLUSION}

Piper nigrum is found in vast altitudinal diversity, and shows great adaptability to a wide range of climatic and soil conditions, which leads to chemometric diversity within the same specie. Essential oils were extracted from the leaves and then run through a GC-MS and scanned against the NIST Mass spectral library 2.0 and the following observations were noted.

Beta Caryophyllene was the only constituent that was present in all the five locations. The highest concentration was found in the high altitude region (HR) of Idukki. Alpha Pinene and Germacrene D were present in 4 out of the 5 Piper nigrum samples collected from the five locations. Samples from Kollam and Ernakulum have similar altitude, rainfall, and temperature levels and hence alpha Cubebene $(1.16 \%, 1.01$ $\%)$, alpha Gurjunene $(1.45 \%, 1.30 \%)$, Gamma Elemene (1.14 $\%, 2.91 \%)$, Eremophilene $(4.32 \%, 4.47 \%)$ and Beta Gurjunene $(12.39 \%, 13.36 \%)$ respectively were found in high concentrations from these two locations. This implies that micro environmental factors (rainfall, altitude and temperature) play a significant role in the production of these compounds. The total volatile oil constituents $(>1 \%)$ ranged from $9-14$ and the highest number of compounds $>1 \%$, were noted in the sample collected from Wayanad. According to a study, (Utpala et al., 2008), 7-15 compounds were detected from volatile oils of Piper nigrum in different regions. According to them maximum variability was observed with respect to Caryophyllene and Nerolidol in the leaf oil of P. nigrum and the influence of location on these components was found significant. It is interesting to note that those samples collected from the nearby geographical region (Idukki LR \& Idukki HR) did not show similar volatile oil profile. Germacrene D (14.34\%) and Alpha Pinene (13.72\%) were found as the major constituents in the oil collected from Idukki (LR) district whereas Elemol $(32.98 \%)$ was found to be the highest in the Idukki (HR). This also shows the influence of location on the production of Germacrene D, Alpha Pinene and Elemol. They all have a characteristic woody fragrance.

\section{ACKNOWLEDGEMENTS}

Thank you to Dr. N S Kalesh and Dr. G R Asish who guided and mentored me thought the experiment. Thank you to all my friends who collected Piper nigrum leaves from their hometowns. 


\section{REFERENCES}

[1] Clevenger, J. F. 1928, Apparatus for the determination of volatile oil. J. Pharm. Sci., 17: 345-349. doi: $10.1002 /$ jps.3080170407

[2] Climate of Kerala, Official Web Portal of Government of Kerala 2014, http://www.kerala.gov.in

[3] ClimateWayanad2014,http://wayanad.nic.in/climate.html
[4] MSN Weather Idukki 2014, http://www.msn.com/enus/weather/today/Idukki,Kerala,India/we-city$9.857,76.963$

[5] Utpala,P., Asish G R., Saji K V, George J K, Leela N K \& Mathew P A 2014, Diversity study of leaf volatile oil constituent of Piper species based on GC/ MS and spatial distribution Journal of Spices and Aromatic Crops.Vol. 23 (1) : $10-16$

[6] WeatherinErnakulum(2014)http://www.accuweather.com len/in/india-weather. 